\title{
The inspiration hold maneuver is a reliable method to assess mean systemic filling pressure but its clinical value remains unclear
}

\author{
Lex M. van Loon ${ }^{1,2}$, Hans van der Hoeven ${ }^{2,3}$, Peter H. Veltink ${ }^{4}$, Joris Lemson ${ }^{2}$ \\ ${ }^{1}$ Cardiovascular and Respiratory Physiology Group, Faculty of Science and Technology, Technical Medical Centre, University of Twente, Enschede, \\ The Netherlands; ${ }^{2}$ Department of Intensive Care Medicine, Radboud university medical center, Nijmegen, The Netherlands; ${ }^{3}$ Radboud Center for \\ Infectious Diseases, Nijmegen, The Netherlands; ${ }^{4}$ Biomedical Signals and Systems, Faculty of Electrical Engineering, Mathematics and Computer \\ Science, Technical Medical Centre, University of Twente, Enschede, The Netherlands \\ Contributions: (I) Conception and design: LM van Loon, H van der Hoeven, J Lemson; (II) Administrative support: LM van Loon; (III) Provision of \\ study materials or patients: LM van Loon, ; (IV) Collection and assembly of data: LM van Loon, J Lemson; (V) Data analysis and interpretation: All \\ authors; (VI) Manuscript writing: All authors; (VII) Final approval of manuscript: All authors. \\ Correspondence to: Lex M. van Loon. Drienerlolaan 5, 7522 NB, Enschede, The Netherlands. Email: lexmaxim.vanloon@anu.edu.au.
}

Background: The upstream pressure for venous return (VR) is considered to be a combined conceptual blood pressure of the systemic vessels: the mean systemic filling pressure (MSFP). The relevance of estimating the MSFP during dynamic changes of the circulation at the bedside is controversial. Herein, we studied the effect of high ventilatory pressures on the relationship between VR and central venous pressure (CVP).

Methods: In 9 healthy pigs under anaesthesia and mechanically ventilated, MSFP was estimated from extrapolated VR versus CVP relationships during inspiratory hold maneuvers (IHMs) with different levels of ventilatory pressure (Pvent). MSFP was measure 3 times per animal during euvolemia and hypovolemia. Hypovolemia was induced by bleeding with $10 \mathrm{~mL} / \mathrm{kg}$. The estimated MSFP values were compared to the blood pressure recording after induced ventricle fibrillation (i.e., mean circulatory filling pressure).

Results: Our results revealed a strong linear correlation between VR and CVP [R2 of 0.92 (range, 0.67-0.99)], during IHMs with different levels of Pvent. Volume status significantly alters the resulting MSFP, $20 \pm 1$ and $16 \pm 2 \mathrm{mmHg}$ for euvolemia and hypovolemia respectively. This estimation of the MSFP was strongly correlated—but not interchangeable—to the blood pressure recording after induced ventricle fibrillation ( $\mathrm{R} 2=0.8$ and $\mathrm{P}=0.045$ ).

Conclusions: In conclusion, we showed a strong linear correlation between VR and CVP—when applying IHMs with high levels of Pvent—however the clinical applicability of this method to guide volume therapy in its current form is improbable.

Keywords: Right atrial pressure; mean systemic filling pressure (MSFP); blood volume; fluid responsiveness; venous return (VR)

Submitted Apr 25, 2020. Accepted for publication Aug 21, 2020.

doi: $10.21037 / \mathrm{atm}-20-3540$

View this article at: http://dx.doi.org/10.21037/atm-20-3540 


\section{Introduction}

Reliably estimating the intravascular volume status to guide fluid therapy in critically ill patients is a clinical challenge. Appropriate fluid therapy will increase cardiac output in order to enhance tissue perfusion and oxygen delivery. However fluid overload results in edema and enhance tissue injury and organ dysfunction (1-5).

Therefore, the search for reliable indicators of both intravascular volume status and fluid responsiveness remains highly relevant (6).

Most available indicators focus on variations of cardiac output in trying to predict fluid responsiveness $(6,7)$. Cardiac output however is restricted by the flow of blood entering the heart, i.e., venous return (VR) $(8,9)$. More insight into VR could prove useful in this respect. VR is determined by the difference between an upstream pressure and the right atrial pressure divided by the resistance to VR (RVR). Conceptually the upstream pressure is regarded as a combined pressure of the systemic vessels (10). This pressure reflects a common pressure that drives blood flow from the vascular beds to the right atrium. Therewith, this pressure could potentially be used as an indicator of the intravascular volume status.

The importance was first recognized by Weber in the 19 th century and he introduced the term 'statischer Füllungsdruck' ('static filling pressure') (11). Starling (12)_ and subsequently Guyton-started using the name 'mean circulatory filling pressure (MCFP)' (13). There is much confusion about this conceptual parameter, not only because of different naming. Mean systemic filling pressure (MSFP), though often confused with MCFP and often similar in value, is considered to be equal by some (14) and different by others (15). In theory, MCFP includes the entire cardiovascular system while MSFP represents the pressure in the systemic circulation only.

Building on work of Versprille (16) and Pinsky (17), Maas et al. revived the interest in the MSFP a decade ago (14). They developed a bedside technique to estimate the MSFP by applying inspiratory hold maneuvers (IHMs) with different levels of static inspiratory ventilatory pressures (Pvent). This technique is based on Guyton's theory of VR, predicting a linear relationship between blood flow and right atrial pressure (16). Extrapolating this relationship between right atrial pressure and cardiac output to zero flow would provide an estimate of the MSFP, in this case the MSFP_IH. Ever since, several studies have used this linear relationship in order to estimate MSFP using IHMs $(14,16,18-22)$. Also, is still unclear if the relationship between blood flow and right atrial pressure is indeed linear in low flow states.

The aim of the present work is to study the MSFP_IH on two aspects: being the relationship between VR and right atrial pressure near zero flow induced by ventilatory pressures and to study the level of agreement between MSFP_IH and blood pressure measurements after cardiac arrest (i.e., MCFP).

We present the following article in accordance with the ARRIVE reporting checklist (available at http://dx.doi. org/10.21037/atm-20-3540).

\section{Methods}

This experiment was performed after approval of the local ethics committee on animal research of the Radboud University Nijmegen Medical Center (RUNMC License number RU-DEC 2014-246) and in full compliance with Dutch and European legal requirements on the use and protection of laboratory animals. A total of 9 domestic piglets [age 3-5 months, mean weight of $36.2 \mathrm{~kg}$ (range, $31-$ $45 \mathrm{~kg}$ ), mean body surface area of $0.8 \mathrm{~m}^{2}$ (range, 0.68-0.89 $\left.\mathrm{m}^{2}\right)$ ] under general anesthesia were studied. In the context of the principles of replacement, reduction, and refinement for the use of animal models, animals used in the study were previously used for medical training (not affecting the cardiovascular system).

\section{Anesthesia and ventilation}

Premedication consisted of the intramuscular administration of midazolam (10 mg/kg), ketamine (1 mg/kg), atropine $(50 \mu \mathrm{g} / \mathrm{kg})$ and amoxicilline $(20 \mu \mathrm{g} / \mathrm{kg})$. Induction of anesthesia was performed using IV administration of propofol $(2 \mathrm{mg} / \mathrm{kg})$. After endotracheal intubation, general anesthesia was maintained using inhalation of isoflurane (0.5-2 volume\%), the continuous IV administration of sufentanil ( $10 \mu \mathrm{g} / \mathrm{kg} / \mathrm{hour})$ and rocuronium ( $1 \mathrm{mg} / \mathrm{kg} /$ hour) after a loading dose of $1 \mathrm{mg} / \mathrm{kg}$.

The lungs were mechanically ventilated using a volumecontrolled mode with tidal volumes of $8-10 \mathrm{~mL} / \mathrm{kg}$, $5 \mathrm{cmH}_{2} \mathrm{O}$ PEEP, $\mathrm{FiO}_{2} 0.4$ and an inspiratory-to-expiratory ratio of 1:2. Ventilation was adjusted according to the end 


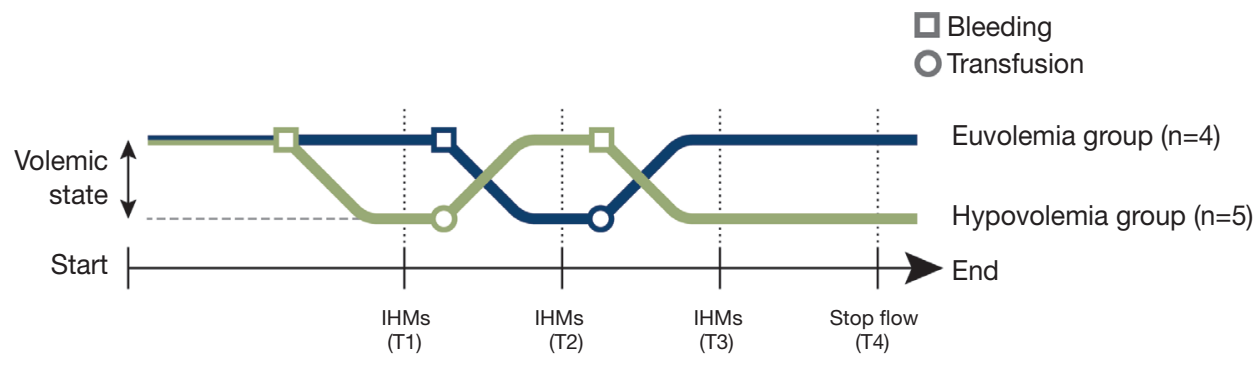

Figure 1 Schematic overview of experimental protocol. In each group, inspiration hold maneuvers (IHM) were performed three times (at T1, T2 and T3) to determine MSFP (MSFP_IH) in different volumetric states and mean circulatory filling pressure after stop flow (T4).

tidal CO2 level (4.5-5.5 kPa).

\section{Surgical preparation}

After receiving premedication, a small peripheral intravenous catheter was placed to administer anesthetics. A central venous catheter (5-7 F, 3-lumen, $13 \mathrm{~cm}$; Arrow International, Reading, PA) was inserted via the right jugular vein close to the right atrium for administration of fluids/medication and central venous pressure (CVP) recording. CVP was used as an approximation of right atrial pressure. This central venous catheter was also used for injection of ice-cold fluid in order to calibrate global enddiastolic volume (GEDV) measurement. An indwelling thermistor-tipped arterial catheter (4-5 Fr, Pulsiocath ${ }^{\mathrm{TM}}$, Pulsion Medical Systems SE) was placed in the lower abdominal aorta via the right femoral artery for arterial blood pressure $(\mathrm{ABP})$ recoding and GEDV assessment (23). All intravascular catheters were inserted by a surgical cutdown technique. The pressure transducers were levelled, zeroed, and placed on the same transducer bar. The zero pressure level and also the anatomical position of the right atrium was considered to be one third of A-P thickness of the chest posterior to the anterior sternal surface (13).

After left thoracotomy, an ultrasound transit-time perivascular flow probe (18 or $22 \mathrm{~mm}$ ) (PAX series, Transonic Systems, Ithaca, NY) was placed around the main pulmonary artery to measure cardiac output. A flow probe is capable of measuring cardiac output continuously also at blood flows near zero. Baseline drift of the flow sensor was checked, including zero flow in vivo, at the end of the experiment. Two temporary cardiac pacing wires leads were placed on the right ventricular epicardium. Last, the chest was closed using multilayer sutures.

\section{Experimental protocol}

At the end of the surgical instrumentation and prior to first intervention we gave a normal saline fluid bolus $(5-10 \mathrm{~mL} / \mathrm{kg}$ ) to treat potential initial hypovolemia related to induction of anesthesia and surgical manipulation. Next, a 30 minutes stabilization period was allowed for all animals. Next, the animals were randomly assigned to start with euvolemia or hypovolemia (Figure 1). Hypovolemia was induced by blood withdrawal of $10 \mathrm{~mL} / \mathrm{kg}$. The shed blood was collected and stored for purpose of retransfusion. During each volumetric state (T1, T2 and T3) several IHMs were performed-after a stabilization period of 30 minutes-by an inspiratory hold of 30 seconds and transpulmonary thermodilution using 3 ice-cold injections for assessment of the GEDV (Figure 1). The duration of the IHM was deliberately longer than the usual 12 second period (14). A run of five (or less when cardiac output approached zero) IHMs were performed at Pvent of 30, 10, 20, 40 and $50 \mathrm{cmH}_{2} \mathrm{O}$ respectively. After the last set of IHMs (at T4) the piglets were euthanized by direct cardiac fibrillation with a $60-\mathrm{Hz}$ alternating current over the cardiac pacing wires, mimicking direct cardiac arrest and zero flow without affecting systemic vascular resistance or compliance. In doing so, 4 of the animals died in a state of euvolemia and 5 in a state of hypovolemia. Before inducing ventricular fibrillation (VF), the endotracheal tube was disconnected from the mechanical ventilator. After inducing VF, both CVP and ABP were continuously recorded. The 
point where $\mathrm{CVP}$ and $\mathrm{ABP}$ equilibrated was considered the MCFP (24).

\section{Data recording}

Electrocardiogram (EKG), hemodynamic/ventilation pressures and flows were continuously recorded on a laptop computer and stored on a hard disk with a sample rate of $200 \mathrm{~Hz}$ by an A/D converter (NI USB-6211, National Instrument, Austin, TX, USA). From these signals, hemodynamic parameters were obtained using customwritten MATLAB scripts. Mean ABP, CVP and cardiac output (from the ultrasound flow probe) were acquired by low-pass filtering of the recorded signals (cut-off frequency of $0.2 \mathrm{~Hz}$, third order Butterworth filter applied in the forward and reverse direction for a zero-phase response). Cardiac output was indexed to body surface area (BSA) using formula $\mathrm{BSA}=0.0734 \times$ body weight ${ }^{0.656}(25)$. HR was acquired by automatic detection of R-peaks from the EKGsignal. From the recorded pressure and flow signal, the pulse pressure variation (PPV) and stroke volume variation (SVV) were calculated offline as described in our previous work (6). The results of the thermal indicator dilution curve were used in the calculation of the GEDV, and was indexed to BSA to acquire GEDVi.

\section{Characteristics of $V R$}

During each IHM, CVP and cardiac output were captured by taking the mean over the last 5 seconds of the maneuver. Next, the set of data points from the IHMs was fitted by linear regression to define the VR curve for each volumetric state. MSFP_IH was then defined as the extrapolation of this linear regression to zero flow, RVR was defined as the inverse of the slope of this linear regression, and VR driving pressure (VRdP) was defined as MSFP_IH minus CVP (prior to the IHMs) (14). Alternatively, RVR was calculated as VRdP divided by cardiac output.

\section{Statistics}

Statistical analysis was performed using MATLAB (Matlab R2019b, The MathWorks Inc., Massachusetts, USA). Normality was assessed using Shapiro-Wilk tests. A pairedsamples $t$-test was conducted to study the influence the volumetric state on all parameters and to compare the consistency of MSFP assessment within animals between moment T1 and T3. Pearson's correlation coefficient was calculated between MSFP_IH and MCFP. Unpaired student $t$-tests were done to check for significant impact of a volumetric state on the MCFP. Data were compared using the method described by Bland and Altman (26). The limits of agreement were calculated by multiplying the standard deviation of the bias with 1.96. The percentage error was calculated by dividing the limits of agreement by the mean value of MSFP_IH and MCFP, times 100\% (27). A P value of $<0.05$ was considered to indicate significance.

\section{Results}

\section{General}

All animals included in the study were considered healthy on physical examination when entering the animals' laboratory and the cardiovascular system was unaffected after being part of medical training. Animals were used in a crossover design, and we randomly assigned to be euthanized either during euvolemia $(n=4)$ or hypovolemia $(\mathrm{n}=5)$.

\section{Volumetric state}

Induced hypovolemia led to an unchanged HR and an expected significant reduction in cardiac output, GEDV and MAP (Table 1). Retransfusion of the collected shed blood restored both MAP and cardiac output back to baseline. These hemodynamic variables were constant between the volumetric state at $\mathrm{T} 1$ and $\mathrm{T} 3$ in all animals. The hypovolemic state was highlighted by significantly higher dynamic indices of fluid responsiveness, including PPV and SVV (Table 1).

\section{Inspirations hold maneuvers (IMHs)}

On average, 4 IHMs were executed per volumetric state (range, 2-5). The IHM with the highest Pvent reduced the cardiac output to $0.4 \mathrm{~L} / \mathrm{min}$ on average (range, $0-1.5 \mathrm{~L} / \mathrm{min}$ ). The Pvent level at which this was achieved depended on the volumetric state, ranging from 30 to $50 \mathrm{cmH}_{2} \mathrm{O}$. A plateau was reached within the 30 -sec of the IHM for CVP (increase) and cardiac output (decrease). Although not used for the assessment of the MFSP_IH, we showed that the $\mathrm{ABP}$ continued to decline and did not reach a 
Table 1 Hemodynamic parameters, characteristics of VR, and dynamic indices per volumetric state

\begin{tabular}{|c|c|c|c|c|c|}
\hline Parameter & \multicolumn{2}{|c|}{ Euvolemia $(n=4)$} & \multicolumn{2}{|c|}{ Hypovolemia $(n=5)$} & $\mathrm{Sig}^{\mathrm{a}}$ \\
\hline \multicolumn{6}{|l|}{ Central hemodynamic } \\
\hline $\mathrm{CO}(\mathrm{L} / \mathrm{min})$ & 3.0 & 1.2 & 2.4 & 0.9 & 0.04 \\
\hline $\mathrm{Cl}\left(\mathrm{L} / \mathrm{min} / \mathrm{m}^{2}\right)$ & 3.9 & 1.5 & 3.1 & 1.0 & 0.05 \\
\hline $\mathrm{PP}(\mathrm{mmHg})$ & 39.2 & 10.2 & 24.7 & 5.8 & $<0.001$ \\
\hline CVP (mmHg) & 11.1 & 5.2 & 8.4 & 4.8 & 0.25 \\
\hline $\mathrm{HR}(\mathrm{bpm})$ & 147.3 & 27.5 & 140.7 & 26.2 & 0.5 \\
\hline $\mathrm{SV}(\mathrm{mL})$ & 42.7 & 13.7 & 33.2 & 8.5 & 0.03 \\
\hline MSFP_IH (mmHg) & 19.9 & 5.1 & 16.3 & 3.6 & 0.04 \\
\hline Venous resistance* (mmHg/L/min) & 3.4 & 2.0 & 3.6 & 1.6 & 1 \\
\hline R-squared & 0.9 & 0.1 & 0.9 & 0.1 & 0.58 \\
\hline VRdP (mmHg) & 8.8 & 2.5 & 7.3 & 2.4 & 0.14 \\
\hline Venous resistance ${ }^{\star *}(\mathrm{mmHg} / \mathrm{L} / \mathrm{min})$ & 3.4 & 1.8 & 3.3 & 1.6 & 0.9 \\
\hline \multicolumn{6}{|l|}{ Dynamic indices } \\
\hline PPV (\%) & 15.4 & 4.1 & 22.3 & 5.7 & $<0.001$ \\
\hline SVV (\%) & 31.0 & 5.6 & 40.2 & 12.8 & 0.02 \\
\hline
\end{tabular}

${ }^{a}$, paired student $t$-test were performed to test for significance between volumetric states. ${ }^{*}$, inverse of the CVP, CO relationship. ${ }^{* *}$, MSFP-CVP, CO. VR, venous return; CO, cardiac output; CI, cardiac index; MAP, mean arterial pressure; PP, pulse pressure; CVP, central venous pressure; HR, heart rate; SV, stroke volume; MCFP, mean circulatory filling pressure; MSFP_IH, estimation of the MSFP using the inspiratory hold method; VRdP, driving pressure of venous return; PPV, pulse pressure variation; SVV, stroke volume variation; GEDV, global end-diastolic volume; GEDVi, indexed global end-diastolic volume.

plateau during the 30 -sec of the IHM, see example Figure $2 A$.

\section{$V R$}

\section{RVR}

The IHM induced decrease in cardiac output and increase in CVP were linearly correlated with a coefficient of determination $\left(\mathrm{R}^{2}\right)$ of 0.92 (range, 0.67-0.99) with no difference between eu- and hypovolemia (Figure $2 B$ ). The correlation between cardiac output and CVP was not improved nor reduced by excluding the IHM with the highest Pvent (at which cardiac output was zero).
Absolute values of RVR (i.e., 1/slope) were not significantly different between eu- and hypovolemia, 3.4 \pm 2.0 and 3.6 \pm 1.6 respectively. Within the eu-hypo-eu group, a large standard deviation in RVR was observed. Still, when RVR was normalized to baseline the RVR was significantly higher during hypovolemia (Figure $3 A, B$ ). When RVR was calculated by dividing VRdP by the cardiac output, similar results were obtained (Table 1$)$.

\section{MSFP_IH}

The MSFP_IH showed a significant difference between eu- and hypovolemia, $19.9 \pm 5.1$ and $16.3 \pm 3.6 \mathrm{mmHg}$ 


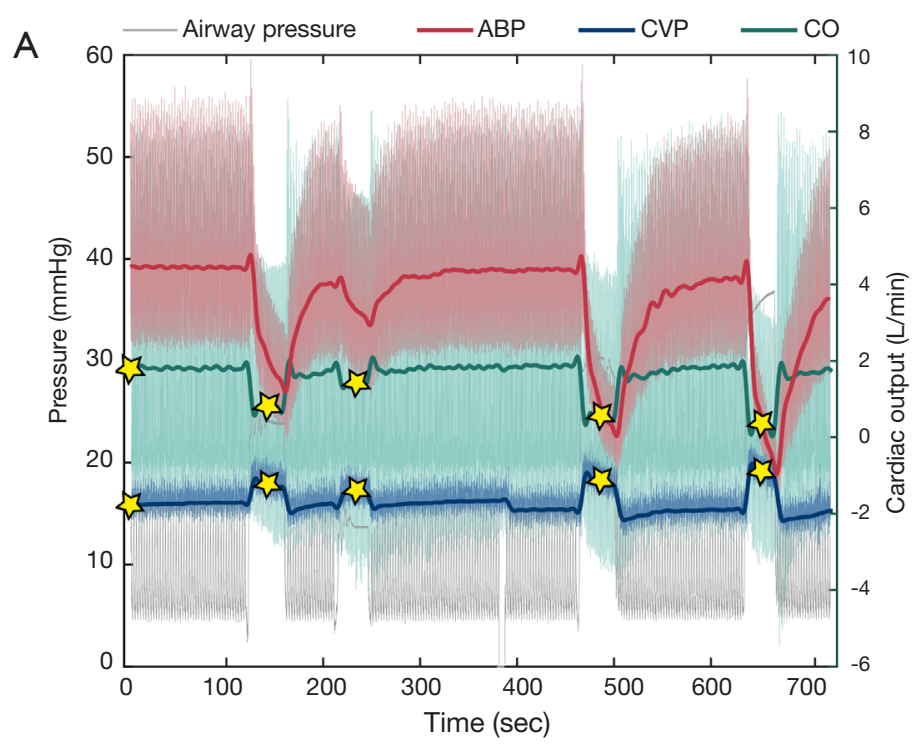

B

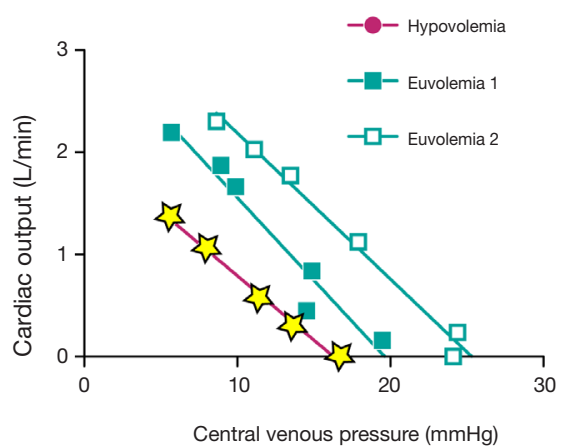

Figure 2 Assessment of the mean systemic filling pressure. (A) Example of piglet 4 during hypovolemia of four inspiration hold maneuvers with ventilatory plateau pressures of $30,10,40$ and $50 \mathrm{cmH}_{2} \mathrm{O}$ respectively at T1. Yellow stars indicate points at which both CVP and cardiac output were taken to construct the VR curve. (B) Three constructed VR curves during different volumetric states in order to estimate the MSFP in piglet 4. Yellow star corresponds to those in panel (A). ABP, arterial blood pressure; CVP, central venous pressure; CO, cardiac output; VR, venous return; MSFP, mean systemic filling pressure.

respectively (Table 1). The MSFP_IH within a piglet was never higher during hypovolemia compared to euvolemia, but no cut-off value could be found to use the MSFP_IH in order to distinguish the volumetric states from each other. A paired-samples $t$-test showed a significant correlation between the MSFP_IH values from T1 and T3.

\section{VR driving pressure}

During hypovolemia, the MSFP_IH was reduced more than CVP, resulting in the VRdP to decrease. Bleeding always led to a reduction in VRdP, but no significant difference in absolute VRdP value was found between the two volumetric states (Figure 3). However, a strong linear relationship $\left(\mathrm{R}^{2}\right.$ of 0.9) between change data of cardiac output and that of VRdP (Figure 4).

\section{MCFP}

VF resulted in an instant drop in ABP, an increase in CVP and no measurable pulmonary flow. The blood pressure signals crossed on average 32-sec after VF. In contrast to MSFP_IH, the MCFP values were not significantly influenced by their volumetric state. Paired Student's $t$-test showed that MSFP_IH, from the latest volumetric state just before inducing VF (T3), was significantly different from MCFP (T4) (Table 1). However, MSFP_IH and MCFP were significantly correlated $\left(\mathrm{R}^{2}=0.8\right.$ and $\left.\mathrm{P}=0.045\right)$ (Figure $5 A$ ). Differences between MSFP_IH and MCFP are shown in the Bland-Altman plots (Figure 5B). The data points in the Bland-Altman plots show a trend, thus the accuracy seemed to be impacted by the level of MCFP. The mean bias was 3.5 $\mathrm{mmHg}$ (limits of agreement $\pm 1.8 \mathrm{mmHg}$ ), the coefficient of variation $17 \%$, and percentage error was $29 \%$.

\section{Discussion}

\section{General}

Our results show a strong linear correlation between VR and CVP, during IHMs with various levels of Pvent up to an almost zero flow state. Indeed, IHMs can be used to determine the MSFP. Also, this MSFP_IH is strongly correlated - but not interchangeable - to the blood pressure recording after induced VF (i.e., MCFP).

\section{MSFP values}

Our MSFP_IH values were in the same range as others have obtained in postoperative patients (19). However, a wide 
A

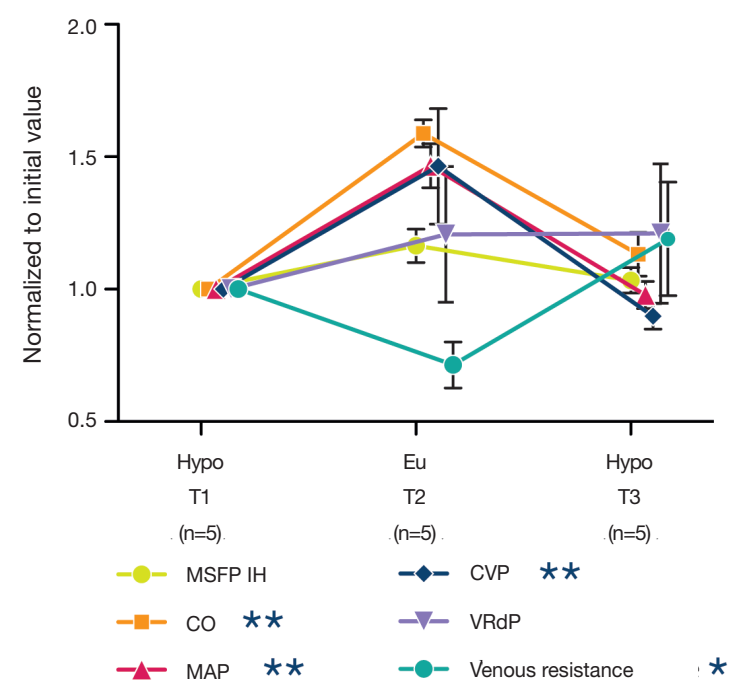

B

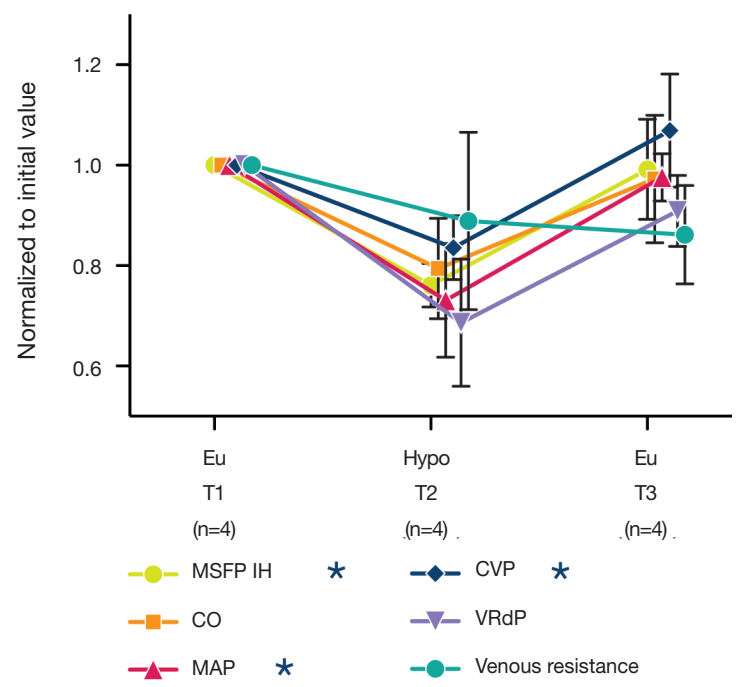

Figure 3 Hemodynamic parameters (normalized to baseline) during the different volumetric states: Eu and Hypo for the both groups [ending in hypovolemia (A) or euvolemia (B)]. Estimation of the MSFP using the inspiratory hold method (MSFP_IH), CO, MAP, CVP, VRdP. Data are expressed as mean and SEM. *, $\mathrm{P}<0.05$; **, $\mathrm{P}<0.01$ (repeated measures one-way ANOVA). Eu, euvolemia; Hypo, hypovolemia; MSFP, mean systemic filling pressure; CO, cardiac output; MAP, mean arterial pressure; CVP, central venous pressure; VRdP, VR driving pressure.

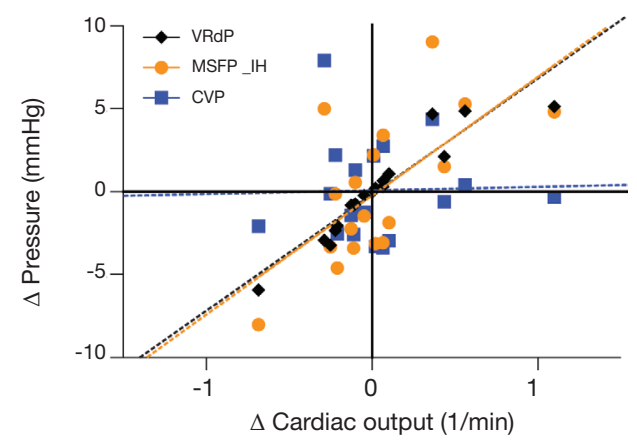

Figure 4 Trend analysis using cardiac output change data versus change data of: VRdP, MSFP (MSFP_IH), and CVP. Dashed lines indicate linear regression line per blood pressure, with a $\mathrm{R}^{2}$ of $0.9,0.4$ and $>0.01$ for VRdP, MSFP_IH and CVP respectively. VRdP, VR driving pressure; MSFP, mean systemic filling pressure; CVP, central venous pressure.

range of MSFP values and many different measurement techniques to estimate this conceptual blood pressure are reported (28-30). Under normal volumetric conditions MSFP_IH values from as low as $8 \mathrm{mmHg}$ in dogs (17), to $11 \mathrm{mmHg}$ in piglets (31), and all the way up to $33 \mathrm{mmHg}$ in septic patients (32) are reported. This wide variation in MSFP values extends even further when alternative measurement techniques-right atrium occlusion (20), arm occlusion $(33,34)$, a model analogue $(30,35-37)$ or cardiac arrest (38)—are considered. Comparing these measurement techniques revealed that they are not interchangeable $(20,35)$, and their accuracy depends on the underlying volume state (39). In this experiment we indeed showed a significant influence of volume status on the MSFP_IH, without finding a cut-off value to discriminate euvolemia from hypervolemia. This is even more troublesome since we established clinically relevant volume differences between the volumetric states. Using normative MSFP values for 

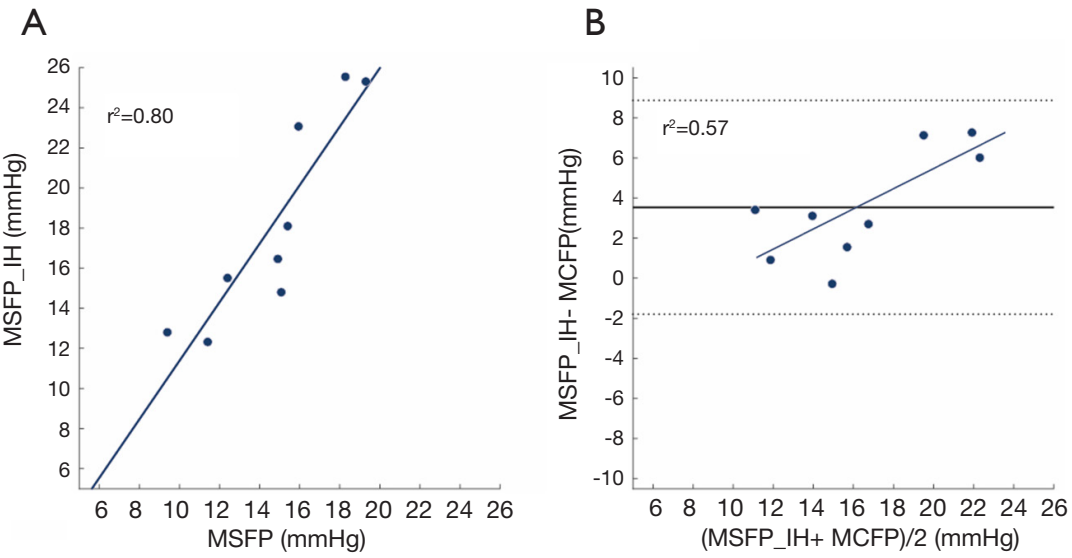

Figure 5 Correlation between MSFP measurements by inspiration hold maneuvers (MSFP_IH) and after ventricular fibrillation (MCFP). (A) Spearman rank correlation $(\mathrm{P}<0.05)$. Continuous line represents linear regression line with regression coefficient $\mathrm{R}^{2}$. (B) Bland-Altman plot. Continuous line represents linear regression line with regression coefficient $\mathrm{R}^{2}$. Dashed horizontal lines represent the limits of agreement. The bold continuous horizontal lines represent the bias.

guiding clinical therapy-when dealing with more subtle differences-remains therefore impractical.

\section{Correlation with MCFP}

Our observed MSFP_IH strongly correlated with the recorded blood pressure after VF (i.e., MCFP), but with a large bias, systematic error, and no correlation with the volume status. Correlation may not necessarily ensure good agreement (26). Suggesting that both parameters are connected, but do not represent the exact same physiological parameter. It is indeed shown that MCFP is not measurable in beating-heart $(24,40)$. Comparing MCFP values between studies is further complicated since the induction of cardiac arrest differs greatly $(24,38,41)$. Especially since these settings-e.g. the way cardiac arrest is induced, (dis)connection from the ventilator, timing, volumetric state, and the presence of externally driving (artificial) shunt between the venous and arterial vesselslikely affected the MCFP by (in)directly intervening with blood volume and/or vasomotor activity. Indeed, Gaddis et al. already pointed out that the way cardiac arrest is induced (either acetylcholine or VF) influences this pressure greatly (42).

\section{Reconstructed VR curve}

We demonstrated that the linear behavior of the constructed VR curve was maintained even when cardiac output was reduced to almost zero by applying IHMs with high levels of Pvent. In clinical practice however, only short holds with moderate ventilatory pressures can be applied since prolonged and high pressures may induce a deterioration of the patient's clinical state (43). Our results showed that the late IHMs with high Pvent did not provide additional information. The presented strong linear relationship between cardiac output and CVP is in line with Guyton's theory on VR (44) and is also observed by multiple studies in both animal models $(16,24)$ and humans $(14,19,45-47)$, while in the past they left room for discussion on the linearity when flow approached zero. However, it remains questionable if these CVP versus cardiac output points are part of one single VR curve (24). The increased intra-alveolar pressures and lung expansion with concurrent increase in pleural and pericardial pressure during an IHM might directly modify the characteristics of the VR curve, by shifting the curve or by modifying its slope (20). This might result in an individual VR curve for each applied IHM (39). Interpreting the characteristics of the acquired VR curve may therefore be misleading because of the (unclear) intervening influence of ventilatory pressures (20).

\section{Clinical implication}

We agree with Guyton that there is a more meaningful upstream pressure for VR than the arterial pressure (48). However, it seems reasonable to conclude that the quest 
for normative MSFP and MCFP values is futile (24,28). Here we demonstrated that within a piglet the MSFP_IH was consistent and linked to the volumetric state, but the absolute value was unsuitable for guiding clinical therapy. The characteristics of this flow-pressure relationship, acquired by using IHMs in a dynamic cardiovascular system, could be seen as dynamic indices rather than the VR curve per se. After all, the underlying theory of Guyton's on VR was not about dynamics. Guyton's formulation of the VR curve was never about MSFP driving VR (48), he only qualitatively predicts the dynamic response from changing right atrial pressure (49). Using IHMs to detect preload-responsive patients has indeed been done before successfully (50).

\section{Limitations}

In addition to the conceptual limitation of estimating the MSFP with the use of IHMs, there are still some experimental limitations. The main limitation comes from the small sample size of the experiment. That being said, the effect sizes supporting the presented conclusions regarding the inspiratory induced hemodynamic perturbations were sufficiently powered. Furthermore, anesthetic drugs and ventilation (disconnection) may have influenced both the assessment of MSFP as well as MCFP. Last, ventilatory pressure did not always reach a plateau level within one inspiratory hold.

\section{Conclusions}

In conclusion, despite a strong linear correlation between VR and CVP-when applying IHMs with different levels of Pvent-the acquired MSFP_IH was related to but did not discriminate between volumetric states. MSFP_IH was not interchangeable with MCFP. Therefore, the flow-pressure relationship using IHMs reflects a dynamic systemic circulatory characteristic rather than an absolute value of the volume state.

\section{Acknowledgments}

The authors like to thank Alex Hansen for his excellent technical assistance.

Funding: This work was supported only by institutional funding.

\section{Footnote}

Reporting Checklist: The authors have completed the ARRIVE reporting checklist. Available at http://dx.doi. org/10.21037/atm-20-3540

Data Sharing Statement: Available at http://dx.doi. org/10.21037/atm-20-3540

Peer Review File: Available at http://dx.doi.org/10.21037/ atm-20-3540

Conflicts of Interest: All authors have completed the ICMJE uniform disclosure form (available at http://dx.doi. org/10.21037/atm-20-3540). The authors have no conflicts of interest to declare.

Ethical Statement: The authors are accountable for all aspects of the work in ensuring that questions related to the accuracy or integrity of any part of the work are appropriately investigated and resolved. This experiment was performed after approval by the local ethics committee on animal research of the Radboud University Nijmegen Medical Center (RUNMC License number RU-DEC 2014-246) and in full compliance with Dutch and European legal requirements on the use and protection of laboratory animals.

Open Access Statement: This is an Open Access article distributed in accordance with the Creative Commons Attribution-NonCommercial-NoDerivs 4.0 International License (CC BY-NC-ND 4.0), which permits the noncommercial replication and distribution of the article with the strict proviso that no changes or edits are made and the original work is properly cited (including links to both the formal publication through the relevant DOI and the license). See: https://creativecommons.org/licenses/by-nc-nd/4.0/.

\section{References}

1. PRISM Investigators, Rowan KM, Angus DC, et al. Early, Goal-Directed Therapy for Septic Shock - A PatientLevel Meta-Analysis. N Engl J Med 2017;376:2223-34.

2. Payen D, de Pont A-CCJM, Sakr Y, et al. A positive fluid balance is associated with a worse outcome in patients with acute renal failure. Crit Care 2008;12:R74.

3. Vincent JL, Weil MH. Fluid challenge revisited. Crit Care 
Med 2006;34:1333-7.

4. Brandt S, Regueira T, Bracht H, et al. Effect of fluid resuscitation on mortality and organ function in experimental sepsis models. Crit Care 2009;13:R186.

5. Rosenberg AL, Dechert RE, Park PK, et al. Review of a large clinical series: association of cumulative fluid balance on outcome in acute lung injury: a retrospective review of the ARDSnet tidal volume study cohort. J Intensive Care Med 2009;24:35-46.

6. Lansdorp B, Lemson J, van Putten MJAM, et al. Dynamic indices do not predict volume responsiveness in routine clinical practice. Br J Anaesth 2012;108:395-401.

7. Magder S. Current tools for assessing heart function and perfusion adequacy. Curr Opin Crit Care 2014;20:294-300.

8. Funk DJ, Jacobsohn E, Kumar A. The role of venous return in critical illness and shock-part I: physiology. Crit Care Med 2013;41:255-62.

9. Funk DJ, Jacobsohn E, Kumar A. Role of the venous return in critical illness and shock: part II-shock and mechanical ventilation. Crit Care Med 2013;41:573-9.

10. Joyce $W$, Wang T. What determines systemic blood flow in vertebrates? J Exp Biol 2020;223:jeb215335.

11. Weber E. On the application of wave theory to the theory of the circulation of the blood and in particular to the pulse [in German]. Arch Anat Physiol 1851;18:497-501.

12. Starling EH. The effects of heart failure on the circulation. Lancet 1897;1:652-5.

13. Guyton AC, Polizo D, Armstrong GG. Mean circulatory filling pressure measured immediately after cessation of heart pumping. Am J Physiol 1954;179:261-7.

14. Maas JJ, Geerts BF, van den Berg PCM, et al. Assessment of venous return curve and mean systemic filling pressure in postoperative cardiac surgery patients. Crit Care Med 2009;37:912-8.

15. Henderson WR, Griesdale DEG, Walley KR, et al. Clinical review: Guyton--the role of mean circulatory filling pressure and right atrial pressure in controlling cardiac output. Crit Care 2010;14:243.

16. Versprille A, Jansen JR. Mean systemic filling pressure as a characteristic pressure for venous return. Pflugers Arch 1985;405:226-33.

17. Pinsky MR. Instantaneous venous return curves in an intact canine preparation. J Appl Physiol 1984;56:765-71.

18. Maas JJ, de Wilde RB, Aarts LP, et al. Determination of vascular waterfall phenomenon by bedside measurement of mean systemic filling pressure and critical closing pressure in the intensive care unit. Anesth Analg 2012;114:803-10.

19. Maas JJ, Pinsky MR, Geerts BF, et al. Estimation of mean systemic filling pressure in postoperative cardiac surgery patients with three methods. Intensive Care Med 2012;38:1452-60.

20. Berger D, Moller PW, Weber A, et al. Effect of PEEP, blood volume, and inspiratory hold maneuvers on venous return. Am J Physiol Heart Circ Physiol 2016;311:H794-806.

21. Wodack KH, Graessler MF, Nishimoto SA, et al. Assessment of central hemodynamic effects of phenylephrine: an animal experiment. J Clin Monit Comput 2019;33:377-84.

22. Berger D, Takala J. Determinants of systemic venous return and the impact of positive pressure ventilation. Ann Transl Med 2018;6:350.

23. Bendjelid K, Giraud R, Siegenthaler N, et al. Validation of a new transpulmonary thermodilution system to assess global end-diastolic volume and extravascular lung water. Crit Care 2010;14:R209.

24. Repessé X, Charron C, Geri G, et al. Impact of positive pressure ventilation on mean systemic filling pressure in critically ill patients after death. J Appl Physiol 2017;122:1373-8.

25. Swindle MM, Smith AC. Swine in the laboratory: surgery, anesthesia, imaging, and experimental techniques. Boca Raton: CRC Press, 2007.

26. Bland JM, Altman DG. Statistical methods for assessing agreement between two methods of clinical measurement. Lancet 1986;1:307-10.

27. Critchley LAH, Critchley JAJH. A Meta-Analysis of Studies Using Bias and Precision Statistics to Compare Cardiac Output Measurement Techniques. Netherlands: Springer, 1999:85-91.

28. Wijnberge M, Sindhunata DP, Pinsky MR, et al. Estimating mean circulatory filling pressure in clinical practice: a systematic review comparing three bedside methods in the critically ill. Ann Intensive Care 2018;8:73.

29. Schulz LF, Geri G, Vieillard-Baron A, et al. Assessment of volume status and volume responsiveness in the ICU: Protocol for an observational, multicentre cohort study. Acta Anaesthesiol Scand 2019;63:1102-8.

30. Cooke K, Sharvill R, Sondergaard S, et al. Volume responsiveness assessed by passive leg raising and a fluid challenge: a critical review focused on mean systemic filling pressure. Anaesthesia 2018;73:313-22.

31. Maas JJ, Geerts BF, Jansen JRC. Evaluation of mean systemic filling pressure from pulse contour cardiac output and central venous pressure. J Clin Monit Comput 2011;25:193-201.

32. Persichini R, Silva S, Teboul JL, et al. Effects of 
norepinephrine on mean systemic pressure and venous return in human septic shock. Crit Care Med 2012;40:3146-53.

33. Geerts BF, Maas J, de Wilde RBP, et al. Arm occlusion pressure is a useful predictor of an increase in cardiac output after fluid loading following cardiac surgery. Eur J Anaesthesiol 2011;28:802-6.

34. Yastrebov K, Aneman A, Slama M, et al. The stop-flow arm equilibrium pressure in preoperative patients: Stressed volume and correlations with echocardiography. Acta Anaesthesiol Scand 2019;63:594-600..

35. Parkin WG. Volume state control - a new approach. Crit Care Resusc 1999;1:311-21.

36. Cecconi M, Aya HD, Geisen M, et al. Changes in the mean systemic filling pressure during a fluid challenge in postsurgical intensive care patients. Intensive Care Med 2013;39:1299-305.

37. Guarracino F, Bertini P, Pinsky MR. Cardiovascular determinants of resuscitation from sepsis and septic shock. Crit Care 2019;23:118.

38. Schipke JD, Heusch G, Sanii AP, et al. Static filling pressure in patients during induced ventricular fibrillation. Am J Physiol Heart Circ Physiol 2003;285:H2510-5.

39. Werner-Moller P, Sondergaard S, Jakob SM, Takala J, Berger D. Effect of volume status on the estimation of mean systemic filling pressure. J Appl Physiol (1985) 2019;126:1503-13.

40. Repessé X, Charron C, Fink J, et al. Value and determinants of the mean systemic filling pressure in critically ill patients. Am J Physiol Heart Circ Physiol 2015;309:H1003-7.

41. Jellinek H, Krenn H, Oczenski W, et al. Influence of positive airway pressure on the pressure gradient for

Cite this article as: van Loon LM, van der Hoeven H, Veltink PH, Lemson J. The inspiration hold maneuver is a reliable method to assess mean systemic filling pressure but its clinical value remains unclear. Ann Transl Med 2020;8(21):1390. doi: 10.21037/atm-20-3540 venous return in humans. J Appl Physiol 2000;88:926-32.

42. Gaddis ML, Rothe CF, Tunin RS, et al. Mean circulatory filling pressure: potential problems with measurement. Am J Physiol 1986;251:H857-62.

43. Mora-Carpio AL, Mora JI. Ventilation, Ventilator Management. Treasure Island: StatPearls Publishing, 2018.

44. Guyton AC. The relationship of cardiac output and arterial pressure control. Circulation 1981;64:1079-88.

45. Keller G, Desebbe O, Benard M, et al. Bedside assessment of passive leg raising effects on venous return. J Clin Monit Comput 2011;25:257-63.

46. Guérin L, Teboul JL, Persichini R, et al. Effects of passive leg raising and volume expansion on mean systemic pressure and venous return in shock in humans. Crit Care 2015;19:411.

47. Maas JJ, Pinsky MR, Aarts LP, et al. Bedside assessment of total systemic vascular compliance, stressed volume, and cardiac function curves in intensive care unit patients. Anesth Analg 2012;115:880-7.

48. Brengelmann GL. Venous Return and the Physical Connection Between Distribution of Segmental Pressures and Volumes. Am J Physiol Heart Circ Physiol 2019;317:H939-53.

49. Moller PW, Winkler B, Hurni S, et al. Right atrial pressure and venous return during cardiopulmonary bypass. Am J Physiol Heart Circ Physiol 2017;313:H408-20.

50. Jozwiak M, Depret F, Teboul JL, et al. Predicting Fluid Responsiveness in Critically Ill Patients by Using Combined End-Expiratory and End-Inspiratory Occlusions With Echocardiography. Crit Care Med 2017;45:e1131-8. 